NBER WORKING PAPER SERIES

\title{
ALTERNATIVE EXPLANATIONS OF THE MONEY-INCOME CORRELATION
}

Ben S. Bernanke

Working Paper No. 1842

\author{
NATIONAL BUREAU OF ECONOMIC RESEARCH \\ 1050 Massachusetts Avenue \\ Cambridge, MA 02138 \\ February 1986
}

I am grateful to Alan Blinder, John Campbell, Gregory Chow, Angus Deaton, Stephen King, Allan Meltzer, Frederic Mishkin, Maurice Obstfeld, and David Romer for valuable comments. The research reported here is part of the NBER's research programs in Economic Fluctuations and in Financial Markets and Monetary Economics. Any opinions expressed are those of the author and not those of the National Bureau of Economic Research. 
NBER Working Paper \#1842

February 1986

Alternative Explanations of the Money-Income Correlation

$\underline{\text { ABSTRACT }}$

Standard explanations of the bivartate correlation of money and income attribute this correlation to an inability of agents to discriminate in the short run between real and nominal sources of price shocks. This paper is an empirical comparison of the standard explanation with two alternatives: 1) the "credit view", which focuses on financial market imperfections rather than real-nominal confusion; and 2) the real business cycle approach, which argues that the money-income correlation reflects a passive response of money to income. The methodology, which is a variant of the Sims VAR approach, follows Blanchard and Watson (1984) in using an estimated, explicitly structural mode1 to orthogonalize the VAR residuals. (Th1s variant methodology, I argue, is the more appropriate for structural hypothesis testing.) The results suggest that the standard explanations of the money-income relation are largely, but perhaps not completely, displaced by the alternatives.

Ben S. Bernanke Woodrow Wilson School Princeton University Princeton, NJ 08544 


\section{Introduction}

By now it should be unnecessary to motivate a study of the statistical correlation between the money stock and national income. At least since the work of Friedman and Schwartz (1963), this stylized fact has been considered among the most important in macroeconomics; at times, its explication has nearly defined the field.

Not too long ago it appeared that there was a developing consensus about the source of this correlation. Lucas (1972) and his followers, on the one hand, and the contract theorists (Fischer (1977), Gray (1978), Taylor (1980)), on the other, developed models which have, conceptually, quite different starting points; yet, operationally, the two approaches have much in common. Both models ascribe the money-income correlation to an inability of agents to discriminate perfectly in the short run between real and nominal sources of price shocks. The two approaches agree that the magnitude of the money-income correlation depends on the relative sizes of the two types of shocks, and both deny that the authorities have the capacity to exploit this correlation to keep output persistently above its natural level. (The contract theorists do differ from the Lucas school in sometimes advocating activist monetary policy in the short run.)

Recently, however, some alternative explanations of the money-income relationship have emerged (or, more accurately, have been revived, since antecedents abound). I consider two of these in the present paper. The first approach, the "credit view", focuses on financial market imperfections rather than real-nominal confusion as the source of the correlation. Shocks to credit markets, whether due to monetary policy or some other source, have (it is argued) effects on real output; since money and credit move together, this shows up as a relation between output and money. 
The second approach, the "real business cycle view," takes the position that money is passive, and that it is correlated with output only because agents increase their demand for transactions services when output or expected future output is high. Advocates of this position can point to recent findings that the money-income correlation is largely a correlation between income and inside money, rather than the base; and that the money-income correlation is greatly reduced when nominal interest rates (which presumably contain information about future output) are controlled for.

To explore these alternative explanations, I use a variant of the Sims (1980a) vector autoregression methodology. This variant differs from the usual VAR approach in the way that it orthogonalizes the estimated VAR residuals into the "true" underlying structural disturbances: Instead of extracting the disturbances via the standard Choleski decomposition (a procedure sometimes treated as neutral, but which in fact embodies strong assumptions about the underlying economic structure), the method used here calculates the disturbances by inverting an estimated, explicitly structural model of the relation among the contemporaneous VAR residuals. This alternative methodology, I argue, is more appropriate to use when attempting to discriminate among structural hypotheses.

The results that I get tend more to the eclectic than the monistic. I present some evidence against recent claims that credit has no role, given money; for the claim that money has no role, given interest rates, I obtain mixed results. It seems appropriate to conclude that the traditional view of the money-income correlation is significantly, but probably not completely, displaced by the alternative theories.

The rest of the paper is organized as follows: Section II discusses the alternative VAR methodology. Section III considers the "credit view" as an 
explanation of the money-income correlation. Section IV examines the real business cycle explanation. Section $V$ concludes.

\section{Methodology}

As will be discussed in more detail in the applications below, much of the new evidence recently advanced on the sources of the money-income correlation has been obtained by the Sims VAR methodology (see particularly Sims (1980b), S. King (1982), 1984), and Litterman and Weiss (1985)). In this paper I will be as concerned with evaluating these recent findings as with presenting additional results; in particular, $I$ am interested in clarifying what, if anything, can be learned about structural hypotheses from the analysis of reduced-form VARs. To facilitate this, this section develops a VAR-type methodology which is similar in form to the standard approach but which admits a more explicitly structural interpretation. A comparison of this methodology with the standard approach raises questions about the value of the latter for structural interpretation of the data. In subsequent sections I also show, by comparing empirical results from the two approaches, that these questions are of great practical importance.

The alternative VAR methodology presented here is closely related to an approach developed by Blanchard and Watson (1984). Following their exposition, let us suppose that $\mathrm{Y}_{t}$ is an $\mathrm{n} \times 1$ vector of macroeconomic variables, observed at time $t$, whose joint behavior we wish to study. (The dimensionality of $Y_{t}$ is typically small: Blanchard and Watson consider a system of four variables. In 
the two applications of the present paper, $n=6$. ) Assume that the dynamic behavior of $\mathrm{Y}_{t}$ is governed by the following structural ${ }^{1}$ model:

$$
Y_{t}=\sum_{i=0}^{\ell} B_{i} Y_{t-i}+A u_{t}
$$

where $u_{t}$, which I will call the vector of "structural disturbances", is serially uncorrelated ${ }^{2}$ and $E\left(u_{t} u_{t}^{\prime}\right)=\Sigma$, a diagonal matrix. In the language of business cycle analysis, the u's are the "impulses" and the $B_{i}$ 's capture the "propagation mechanism" of the economy. (2.1) generalizes Blanchard and Watson's equation (1) by allowing $A \neq I$. A is an $n \times n$ non-singular matrix whose diagonal elements are normalized to equal one but which may have arbitrary off-diagonal elements.

Writing the stochastic component of (2.1) as $A u_{t}$, under the assumptions made, imposes no restrictions relative to the usual Cowles formulation that takes $\mathrm{A}=\mathrm{I}$ and allows the contemporaneous covariance matrix of the $\mathrm{u}^{\prime} \mathrm{s}$ to be arbitrary. I have chosen the less familiar representation in order to convey a somewhat different interpretation than the usual of the nature of the u's and of the sources of correlation between structural equations: Specifically, I

1 In this paper I use "structural" in the traditional sense of "motivated by an explicit economic theory" rather than in the more modern usage, "invariant with respect to a specified class of interventions." Thus the models I will estimate are vulnerable to the Lucas critique. Note, however, that $I$ do not use my results to make conditional forecasts, but only to assess the relative importance of certain types of shocks during a given sample period; the latter is a valid application. I thank Lars Hansen and Frederic Mishkin for raising this point.

2 Serial correlation of $u_{t}$ could be handled by standard methods. I rule this out here only so that the alternative methodology given here will be more directly comparable to the conventional VAR approach. 
want to think of the u's in (2.1) as "primitive" exogenous forces, not directly observed by the econometrician, which buffet the system and cause oscillations. Because these shocks are primitive, i.e., they do not have common causes, it is natural to treat them as approximately uncorrelated ( $\Sigma$ diagonal). However, one would not want to restrict individual u's to entering one and only one structural equation, in general; thus the matrix $A$ is allowed to have arbitrary off-diagonal elements. Under this interpretation, then, the stochastic parts of individual structural equations are allowed to be contemporaneously correlated in an arbitrary way; however, the correlation between any two equations arises explicitly because the equations are influenced by one or more of the same fundamental shocks $u_{t}{ }^{3}$

As an example, one element of $u_{t}$ might represent supply conditions in the world oil industry. This exogenous influence on a given national economy should be at least approximately uncorrelated with other fundamental macroeconomic influences, such as the pace of domestic technical or financial innovation, or the random components of monetary and fiscal policy. Thus $\Sigma$ is diagonal. However, oil supply conditions might well affect a number of different structural equations (e.g., both aggregate supply and aggregate demand). Thus in this case A has off-diagonal elements and the stochastic components of different structural equations are correlated.

Note that, in taking $A$ to be $\mathrm{n} x \mathrm{n}, \mathrm{I}$ am assuming that the number of observed macro variables $Y_{t}$ and the number of unobserved fundamental shocks $u_{\text {first, }}$ are the same. This is not as restrictive as it appears: First, if the observed macro variables are independent in the sample, then (2.1) implies that there must be at least as many independent shocks as observed variables. (Some of the shocks might only be measurement errors.) If the number of fundamental shocks exceeds the number of observed variables, then the independent influences of all of these shocks cannot be identified. However, it will always be possible in this case to pick $n$ independent shock series and an associated A matrix which imply observational equivalence with the true structure. 
This discussion suggests a potentially valuable payoff to estimating the model (2.1): Given the estimated parameters, (2.1) can be used to obtain time series of estimated fundamental disturbances $\hat{u}_{t}$. Since this model is supposed to be structural, it should be possible to give these estimated shocks fairly specific economic interpretations (e.g., as shocks to aggregate demand, aggregate supply, or to policy reaction functions). As do Blanchard and Watson in their paper, one could then study (1) the occurrence of specific individual shocks (as an aid to interpreting economic history), (2) the joint empirical distribution of the shocks (in order to examine more general hypotheses about the sources of cycles), and (3) the dynamic response of observed macro variables to a representative shock of a given type.

A problem is that (2.1) has potentially a great many unknown parameters. Blanchard and Watson note that a computational simplification in estimating (2.1) is achieved if we impose no restrictions on the $B_{i}$ for $i>0$ (except for specifying the maximum lag length) and concentrate on modelling contemporaneous relationships. ${ }^{4}$ In this case a reduced form relating $\mathrm{Y}_{\mathrm{t}}$ to its lagged values can be written

$$
Y_{t}=\sum_{i=1}^{\ell} c_{i} Y_{t-i}+y_{t}
$$

where $C_{i}=\left(I-B_{0}\right)^{-1} B_{i}$ and $y_{t}$ is a serially uncorrelated vector of residuals. The vector $y_{t}$ satisfies

$$
y_{t}=B y_{t}+A u_{t}
$$

4

For the models estimated by Blanchard-Watson and in this paper, it seems reasonable to impose no restrictions on lag structures. This is also what is done in the standard VAR approach. One can imagine models based on dynamic economic theories, however, for which restrictions on lags would provide important identifying power. 
where $I$ now write simply $B$ instead of $B_{a}$. Once estimated $y_{t}^{\prime} s$ are obtained from a first-stage, unrestricted estimation of $(2.2)^{5}$, one may attempt to identify and estimate the purely contemporaneous structural model given by (2.3).

Before discussing the details of how (2.3) is estimated, it will be useful to consider the relation of the foregoing to coventional VAR analysis.

The interpretation of VARs. ${ }^{6}$ The value of Sims' $(1972,1980$ a) VAR methodology for forecasting, or for providing an atheoretical characterization of patterns in the data (such as might also be given by estimated spectra, or by Burns-Mitchell reference cycles) is uncontroversial. Much less clear is the ability of unrestricted VARs to aid in discriminating among structural hypotheses about the economy. Nevertheless, many recent studies appear to be operating on the premise that the calculation of Granger-causality tests, variance decomposition tables, and impulse response functions is helpful for distinguishing true theories from false ones. It is useful to reconsider this premise for the case in which (2.1) describes the true structure. Since the question of what can be inferred from a finding of Granger causality has been extensively debated (see, e.g., Zellner (1979) and Leamer (1985)), I concentrate on the interpretation of estimated variance decompositions and impulse response (IR) functions within this framework. However, it should be

In this paper I estimate (2.2) as a standard vector autoregression. Because of a difference in focus, Blanchard and Watson estimate (2.2) by a method that reduces the weight given to outliers.

Everything in the subsection below is at least implicit in the Blanchard-Watson paper, but I believe that an expanded discussion and further emphasis are warranted. See Gordon and King (1982) for a good related analysis. Also, after writing this paper I became aware of work by Cooley and LeRoy (1985), which gives a very nice presentation of a number of similar points. 
clear that the interpretation of Granger-causality tests is also affected by the considerations discussed below. ${ }^{7}$

Let us review some basics of how variance decompositions and IR functions are calculated. The first step is relatively innocuous; it is simply the estimation of a VAR (like (2.2)) and the obtaining of residuals (the $y_{t}$, in our notation). However, the more troublesome next step (required to construct unambiguous variance decompositions or IR functions) is to decompose the $y^{\prime} s$ into $\mathrm{n}$ orthogonal time series. There is perhaps no one correct way to do this. However, since these new orthogonal series are treated as being economically meaningful by proponents of the standard VAR methodology, I would argue that what is really wanted are the $u^{\prime} s$ from equation (2.3). To obtain estimates of these u's, it appears necessary to use the relevant econometric theory to identify and estimate the model (2.3). This of course requires a commitment to a specific structural model (or, perhaps, to a class of models).

Practitioners of the standard VAR approach do not use the explicitly structural method just described to orthogonalize the VAR residuals, presumably because of the view of Sims (1980a) that a sufficient number of credible identifying restrictions are not typically available. But does the standard VAR approach in some way achieve a meaningful decomposition of the $y^{\prime} s$ without assuming a specific structural model? The answer is no: Indeed, the conventional method of orthogonalization (based on the Choleski decomposition) is equivalent to assuming a model of the form of (2.3) in which $\hat{A}=I$ and, for a specified ordering of the variables, $\hat{B}$ is a lower-triangular matrix of projection coefficients. This achieves orthogonalization of the residuals, but it also has the effect of assuming that the structural model for $y$ is of a 
particular form, i.e., strictly recursive--an assumption which is usually not motivated by the relevant economic theory. The essential arbitrariness of the conventional approach is not helped by the usual practice of trying alternative orderings of the $y^{\prime} s$ : This still restricts attention to recursive models, which (roughly speaking) occupy a set of measure zero within the set of models described by $(2.3)^{8}$.

If it is not believed that the true economic model is recursive, then the orthogonal "shock" series obtained by the conventional approach have no particular meaning. This outweighs what otherwise would be attractive arguments that a standardized method of orthogonalization reduces investigator discretion and thus the scope for "data-mining." There seems to be no alternative, if one wishes to interpret calculated variance decompositions and IR functions as giving evidence about the structure of the economy, to identifying and estimating explicitly structural models of the form (2.3) and then using the associated $\hat{u}^{\prime} s$ as the orthogonal decomposition of the $y^{\prime} s$. In the next sub-section I discuss how models of the form (2.3) may be estimated; in the empirical applications below I demonstrate that orthogonalization via an estimated model, rather than by an assumed recursive structure, can have a significant effect on the inferences drawn from a VAR-based analysis.

Estimation of (2.3) . Given that the vector of residuals $y_{t}$ has been obtained from a first-stage VAR, the problem of interest is how to estimate the system of equations (2.3). This system of equations may usefully be thought of

8

of course, assuming a recursive model for $\mathrm{y}$ is defensible if one actually believes that the structure (2.3) is recursive. However, the practice of trying different orderings is consistent only if the investigator believes the system to be recursive but does not know the causal sequence. This is a very strange sort of prior. 
as a latent variables mode1; it is closely related to factor models and index models. In the macro literature, models of this form have been estimated by $R$. Ha11 (1978), Hall and Mishkin (1982), Bernanke (1983a, 1984) and no doubt by others. (For an estimated macroeconomic index model, see Sargent and Sims (1977).) All of the papers above estimate lagged as well as contemporaneous relationships, and there is no reason in principle why prior restrictions on the lag structure could not be incorporated into the present analysis (e.g., they could take the form of restrictions on (2.1) and (2.2)). However, as noted above, prior restrictions on the lag structures seem relatively less credible for the models estimated here, and I do not employ them.

Although overidentified models of the form of (2.3) can be estimated by maximum likelihood methods (see B. Hall (1979)), in this paper I consider only just-identified models, for three reasons: First, I will show that just-identified versions of (2.3) can be estimated by a simple and well-known method which is computationally much less onerous than general maximum likelihood with overidentifying restrictions (give the number of unknown parameters typically involved in systems of any size). Second, overidentified models will not in general yield perfectly orthogonal $\hat{u}$ 's, so that the problem of how to order variables in variance decompositions and IR functions re-emerges (albeit in a relatively minor way, since if the overidentifying restrictions are not rejected, the departure from orthogonality is small). Third, in practice one rarely enjoys the luxury of having many substantive overidentifying restrictions; indeed, some of the assumptions needed to identify are typically "auxiliary" assumptions, in that they are not strongly implied by the basic theory. (For example, it may be assumed that the disturbances associated with certain structural equations are uncorrelated.) 
The use of just-identified models in practice thus tends to minimize the number of auxiliary assumptions employed.

The model in Blanchard Watson is just-identified (given that two parameters are estimated using information from outside the data set), but it also contains two special features: 1) The assumption that disturbances to the model's equations are uncorrelated cannot be relaxed ( $A=I$ in (2.3)). 2) The model is "quasi-triangular"; i.e., the equations can be ordered in such a way that each equation $i$ has exactly i-1 unknown parameters. ${ }^{9}$ These two features allow the Blanchard-Watson model to be estimated by sequential application of two-stage least-squares, where the instruments for the $i-t h$ equation are the estimated residuals from equations 1 through i-1.

I avoid imposing these special features by estimating using the method of moments; that is, I equate the population moments implied by the theory with the sample moments of $y$ (where, again, $y$ is the vector of VAR residuals). From (2.3) it follows that

$$
u_{t} u_{t}^{\prime}=A^{-1}(I-B) y_{t} y_{t}^{\prime}(I-B)^{\prime}\left(A^{-1}\right)^{\prime}
$$

Let $M=\frac{1}{T} \sum_{t} y_{t} y_{t}^{\prime} \quad$ be the sample covariance matrix of $y$.

Then averaging (2.4) over the sample and equating population moments and sample moments yields

$$
\hat{\Sigma}=\hat{A}^{-1}(I-\hat{B}) M(I-\hat{B}) \cdot\left(\hat{A}^{-1}\right)^{\prime}
$$

where (2.5) now defines the estimates $\hat{\Gamma}=(\hat{A}, \hat{B}, \hat{\Sigma})$, if the system is identified. 
The individual parameters (the non-zero elements of $\hat{\Gamma}$ ) will generally be identifiable under two conditions: First, the number of estimated parameters must not exceed the number of distinct covariances in $M$ (an order condition). ${ }^{10}$ The number of distinct covariances is $n(n+1) / 2$; thus, in the $(6 \times 6)$ models estimated below I am able to identify 21 parameters--the 6 diagonal elements of $\Sigma$ and 15 nonzero elements of $\mathrm{A}$ and $\mathrm{B}$. The second condition is that the system of nonlinear equations given by (2.5) have at least one solution. This may fail: For example consider the model specification in which it is assumed that the $i-$ th and $j$-th row of $B$ contain only zeros, for some distinct $i$ and $j$, and that non-diagonal elements of the $i-t h$ and $j$-th rows of $A$ are also zero. Then there are no possible parameter values which yield a non-zero population covariance for the $i-t h$ and $j$-th elements of $y$; this prohibits a solution if the corresponding sample covariance is non-zero. I think of this second condition as a rank condition, since if the matrix of partial derivatives of the distinct population covariances with respect to unknown parameters is everywhere of full rank, a solution can be typically obtained.

If all parameters are identified, the estimates are obtainable numerically in two steps: 1) To find the $n(n-1) / 2$ non-zero parameters of $\hat{A}$ and $\hat{B}$, first set all below-the-diagonal elements of the symmetric matrix on the right-hand-side of (2.5) equal to zero. (Recall that $\hat{\Sigma}$ is constrained to be a diagonal matrix.) This yields a system of $n(n-1) / 2$ simultaneous equations in the same number of unknown parameters of $\hat{A}$ and $\hat{B}$. This system is typically well-behaved and is easily solved. 2) Given the elements of $\hat{A}$ and $\hat{B}$, read off the estimated non-zero values of $\hat{\Sigma}$ from the diagonal of the matrix on the right-hand-side of (2.5). This process is computationally very easy: Model 
estimates presented in this paper were obtained in an average (per specification) of less than one minute of computing time on a personal computer.

This estimation procedure is numerically identical to Blanchard and Watson's sequential 2SLS procedure, for the cases where that procedure is applicable. The estimates are consistent no matter what distributional assumptions are made (as long as all the relevant moments exist); if an assumption of normality of the structural disturbances $u$ is added to the maintained assumption of just-identification, the method-of-moments (MOM) estimates are also numerically identical to the maximum likelihood estimates (see B. Hall (1979)). Indeed, because the first-stage VAR is also an MOM estimator, and because we are considering only just-identified models, the previous statement applies to the full two-stage estimation procedure (including the estimation of (2.2)), as well as to the estimation of (2.3) considered in isolation. That is, the parameter estimates obtained by the two-stage procedure are identical to those one would get by applying FIML to the original model (2.1).

I estimated standard errors of the parameters in two ways. First, I calculated the appropriate asymptotic sampling error of the covariance matrix of VAR residuals, M, by methods described in Anderson (1958), chapter 8 . Since the parameter estimates are functions of $M$, their approximate standard errors could be computed directly from the standard errors of the elements of $M$ via a linearization. Second, I estimated standard errors by inverting the information matrix of the maximum likelihood problem associated with (2.3) for the case where the u's are independent normals. The first of these methods explicitly takes into account the two-stage nature of the estimation (i.e., the standard errors obtained should be approximately equal to those derived by 
applying FIML to (2.1)), while the second method treats (2.3) as the basic estimation problem and ignores the first-stage VAR. For this reason, t-statistics derived by the first method are reported below. However, standard errors obtained by the two methods differed only very slightly.

Given estimates $\hat{A}, \hat{B}$, and $\hat{\Sigma}$, and the model (2.3), one can construct structually interpretable decompositions of the VAR residuals into orthogonal shocks. The implications of this for the interpretation of VARs are developed in the two applications below.

\section{Money versus Credit}

In this section I take up the first of the two alternative explanations for the money-income correlation; namely, that this correlation is in some sense "rea11y" a correlation between income and credit (at least in part) so that the strong bivariate correlation of money and output reflects primarily the collinearity of money and credit. ${ }^{11}$ Some empirical evidence for the credit view (where credit is defined very broadly) has been offered in various places by Benjamin Friedman (see e.g., Friedman (1983)). Counter-evidence is given in an interesting paper by Stephen King (1984); I will return to the King paper below.

To anticipate a bit the next section's discussion of real business cycles: A possible view of the money-versus-credit issue is that it is unimportant, because both money and credit are purely endogenous, not causal variables. A clear recent statement of this may be found in R. King and Plosser (1984): In the King-Plosser mode1, financial services (transactions, borrowing) are inputs

11 The notion that the money-income correlation is in fact due to the relation of some omitted third variable to both money and income arises again when we consider the real business cycle hypothesis, below. 
into the production process; as with any normal input, financial services are used more heavily when output is high or is expected to be high. In this framework, financial aggregates such as money and credit appear to lead output (or to be contemporaneously correlated with output) because these aggregates mirror the level of financial services; however, the financial aggregates are purely passive responders to movements in current output and expected future output. Roughly, money and credit appear at the bottom of a block-recursive system. 12

If money and credit are passive tails on the output dog, then the issue of money-versus-credit is of little practical importance, except perhaps for forecasters. Is the real business cycle view plausible? It does seem likely to me that on average, much if not most of the relation of income and the financial aggregates might be due to endogeneity of the aggregates. (This turns out to be important for interpreting the empirical results below.) However, for purposes (say) of policy analysis, there is a big difference between complete and almost-but-not-quite-complete endogeneity of the financial aggregates, since it is in those occasional circumstances when the direction of causality runs from financial aggregates to output that correct policy choice is most important. Thus, while acknowledging that money and credit are probably often passive, I shall proceed to consider the possibility that these variables may sometimes take an active, causal role.

Some currently standard explanations of how monetary shocks can have real effects were mentioned in the introduction. Analyses of the macroeconomic about the money-income correlation as pertaining to real, as opposed to nominal, money (or credit). A positive relation between output and real money implies a similar relation between output and nominal money if prices are not too countercyclical. See King and Plosser for an extended discussion of this point. 
effects of credit shocks are contained in Blinder (1983), Bernanke and Gertler (1985), and others; for a particularly clear and simple discussion, see Blinder and Stiglitz (1983). ${ }^{13}$ Without going into detail, I will here state and discuss briefly some basic features of the canonical credit-causes-output story. For theoretical reasons (see below), by "credit" I will mean specifically customer loans granted by intermediaries, not bonds or other auction-market instruments, despite Friedman's results that broader measures of credit track output more closely.

The argument for credit appears to have two major and two auxiliary premises. The two major premises are:

1) Some assets of financial intermediaries (specifically, their customer loans) are imperfect substitutes for non-intermediary assets; in particular, only intermediaries are willing to hold the liabilities of certain borrowers.

2) There are shocks which affect the cost and availability of funds to financial intermediaries; there are also shocks to the cost of the intermediation process itself.

Imperfect substitutability of intermediary and non-intermediary assets (Premise 1) is supposed to arise because of imperfect information in credit markets (see Blinder and Stiglitz). Intermediaries specialize in the provision of credit to borrowers who, because of high screening and monitoring costs, cannot easily obtain funds by issuing securities on the open market. Because moral hazard problems prevent intermediaries from credibly conveying the information they have about their assets, non-intermediaries will purchase of financial intermediation in the real economy. See particularly Townsend (1983) and Boyd and Prescott (1983). 
these assets only at a discount, if at all. ${ }^{14}$ Nor will non-intermediaries often make new intermediary-type loans, both because of their cost disadvantage in making such loans and because of the unfavorable signal projected by potential borrowers who have not been able to obtain loans from intermediaries. The result is that, if intermediaries become for some reason unable or unwilling to make new loans, certain types of borrowers may find it very difficult to obtain credit, at least in the short run.

That intermediary assets are to some degree nonsubstitutable with other assets would seem hard to deny. (See Fama (1985) for some direct evidence on this question.) The key issue, which can only be resolved empirically, is one of degree: If the capacity of some intermediary or set of intermediaries to make loans is reduced, how quickly and with what premium will alternative lenders fill the gap? This question is often of direct policy importance: For example, it has been debated whether regulations that permit savings and loans improved access to sources of funds have any effect on the housing industry (Jaffee and Rosen (1979), Hendershott (1981)). The effect on housing will be larger, the harder it is for builders to find alternative mortgage lenders.

The shocks that may hit the intermediation system (Premise 2) are of several sorts. Blinder and Stiglitz emphasize the effects of changes in monetary policy (e.g., draining of reserves, changes in reserve requirements). A second major category of possible shocks is those due directly or indirectly to financial regulation: the disintermediation that occurred when market interest rates exceeded regulation $Q$ ceilings, the introduction of money market certificates, changes in regulations concerning portfolio composition, credit

New instruments such as mortgage-backed bonds do not invalidate this statement. These instruments are made feasible only by very high rates of collateralization and by government and institutional guarantees against default. See Bernanke and Gertler (1985), p. 38. 
controls, usury ceilings, etc. A third type of possibility is changes in the public demand for intermediary liabilities (e.g., deposits), when these changes are for some reason (regulatory or otherwise) not easily offset by issuance of alternative liabilities (such as certificates of deposit). ${ }^{15}$ Fourth, we may treat as shocks financial innovations (e. 8., new lending instruments) or technical changes (computerization) that affect the cost and scope of the intermediation process.

If we are willing to construe "credit shocks" broadly, there is a fifth category of shock to include; namely, shocks to the solvency and creditworthiness of borrowers. Consider an event like the deflation of the 1930s or the combined disinflation and exchange rate appreciation that afflicts farmers and other exporters in the 1980s. Since the forcing of bankruptcy proceedings is a punitive measure designed to provide the individual borrower an incentive for effort ex ante, in an ideal debt contract the probability of bankruptcy would be independent of the occurrence of events like these which are clearly out of the borrower's control. Evidently, debt contracts do not have this property, since bankruptcy rates are sensitive to aggregate phenomena like the business cycle. When the rate of insolvency is generally high, it becomes much riskier for intermediaries to make new loans, even for intrinsically worthwhile projects; a typical response to this situation is for intermediaries to employ tighter and more costly screening procedures, or to retreat from new credit extension entirely. Arguably, then, imperfectly indexed debt contracts and the institution of bankruptcy can lead, under some rapid declines in deposits may affect the capacity of intermediaries to function normally. See Bernanke (1983b). 
circumstances, to a lower level of lending and investment then would be justified by "fundamentals" (e. g., in an Arrow-Debreu economy). 16

Together, Premises 1 and 2 imply that "credit shocks" will have real effects on the economy. For example, a rise in market interest rates above the regulation $Q$ ceiling may induce a loss of thrift industry deposits and a decline in mortgage lending. If 1) this decline can not be offset in the short run by alternative lenders, and 2) if the fall in construction is not replaced in the short run by other types of spending, then the resulting fall in aggregate demand may contribute to a recession. ${ }^{17}$ Then credit and output will be correlated for two reasons: first, because of the endogeneity of credit over the cycle (the dominant effect?); and second, because occasional shocks to the credit intermediation process have a causal relation with output.

I mentioned that there are also two "auxiliary premises" to the credit-causes-output story. These are the existence of equilibrium credit rationing (Jaffee and Russell (1976), Stiglitz and Weiss (1981), Blinder and Stiglitz, Blinder (1984a, 1984b), S. King (1984)) and of sticky prices (Blinder and Stiglitz, Blinder (1984a)). Although many of the cited references treat these two hypotheses as centra1, neither is in fact strictly necessary to motivate real effects of credit shocks. They do, however, help at certain key points: The existence of credit rationing may explain how credit shocks affect output without inducing large swings in lenders' interest rates. Sticky prices economy, see Fisher (1933). Also see Bernanke (1981, 1983b). via aggregate demand to be the more plausible. However, aggregate supply effects are possible; see Blinder (1984a). 
may be essential to a model in which open-market operations in particular have real effects via credit markets. ${ }^{18}$

Evidence for the Credit-Shock Model. There has been little systematic empirical work on the relation of credit and output. The cited paper by Friedman, plus several others he has written, finds the strongest relationship between credit and output when very broad measures of credit (measures which, unfortunately, are rather hard to justify theoretically) are used; he finds much less correlation between output and measures of intermediary credit. ${ }^{19}$ Particularly damaging to the credit hypothesis are results obtained by $\mathrm{S}$. King (1984). Using commercial and industrial (C\&I) loans made by commercial banks as his measure of credit, King employed standard VAR techniques to show that 1) credit has little addtional predictive power for GNP when measures of money are included, but money is a powerful output predicter; and 2) the decomposition of the forecast variance of output at a four-year horizon shows little role for credit shocks, while money, again, plays an important role. Observing that these results obtain in monthly as well as quarterly data, King concluded that the credit-oriented explanation of the money-income relation has little empirical support.

A possible alternative model motivating real effects of open market operations, that does not assume a sticky price level, could be based ( $I$ conjecture) on the fact that deposits and loans are set in nominal terms and on the hypothesis that people adjust nominal deposit and credit balances only gradually in response to shocks (a buffer stock model). Note also that if we exclude open market operations as a source of credit shocks (and there is some evidence for this given below), this eliminates only one type of shock from the list that has been offered.

Porter and Offenbacher (1983) use VAR techniques to question the strength of the credit-output relationship for even Friedman's favored measure of credit. They are careful not to draw structural inferences, however. 
There are two possible problems with King's results. The first is that his measure of credit is not sufficiently inclusive (indeed, he presents evidence that "other" commercial bank loans may have more predictive power for GNP than do C\&I loans). The second, discussed below, is the general criticism of the standard VAR methodology already raised in Section II.

To see if the narrowness of King's credit measure was a problem, I performed a standard VAR analysis using two alternative (more inclusive) credit variables: the log of total commercial bank loans, in nominal terms (CB), and the $10 \mathrm{~g}$ of the sum of loans made by commercial banks, savings and loans, and mutual savings banks, also nominal (C). The results were quite similar in the two cases; I report only the outcomes using $C$. The other variables in the VAR were the logs of real GNP (Y), the GNP deflator (P), real defense spending ( $G$ ), the monetary base (B), and $M 1$ (M).$^{20}$ As a check for robustness, and for other reasons discussed below, I estimated the VAR system both in log-levels (with a constant and a trend) and in log-differences, i.e., rates of growth (with a constant). The data are quarterly, from 1953:I to $1984: I V$; since I allowed four lags for each variable, the sample begins in 1954:I for the level data and 1954 : II for the differenced data. ${ }^{21}$

Results of this exercise are contained in Tables 1, 2, and 3 . These tables tend to confirm King's findings. Table 1 shows that credit is marginally predicted at the .05 level by real output, defense spending, and $M 1$; it marginally predicts no other variable at the .10 level. GNP is predicted at

The data appendix contains more discussion of data and sources. Recent research suggests that an interest rate should be included in this system. I consider this separately in the next section. allow for possible problems with the deseasonalization procedures, did not affect the results. 
Table 1. Tests of Marginal Predictive Power of Row Variables for Column Variables.

a. Log-Levels, 1954:I - 1984:IV

$\begin{array}{ccccccc} & \mathrm{Y} & \mathrm{P} & \mathrm{G} & \mathrm{B} & \mathrm{M} & \mathrm{C} \\ \mathrm{Y} & & & & & & .000 \\ \mathrm{P} & .000 & .402 & .745 & .813 & .612 & .198 \\ \mathrm{G} & .237 & .000 & .585 & .189 & .136 & .020 \\ \mathrm{~B} & .012 & .169 & .000 & .862 & .612 & .250 \\ \mathrm{M} & .106 & .265 & .448 & .000 & .303 & .042 \\ \mathrm{C} & .003 & .723 & .328 & .605 & .000 & .000\end{array}$

b. Log-differences, 1954:I - 1984:III

$\begin{array}{ccccccc} & \mathrm{Y} & \mathrm{P} & \mathrm{G} & \mathrm{B} & \mathrm{M} & \mathrm{C} \\ \mathrm{Y} & & & & & & .282 \\ \mathrm{P} & .000 & .289 & .584 & .708 & .001 \\ \mathrm{G} & .033 & .000 & .682 & .799 & .266 & .233 \\ \mathrm{~B} & .014 & .217 & .024 & .893 & .300 & .003 \\ \mathrm{M} & .139 & .011 & .848 & .018 & .904 & .059 \\ \mathrm{C} & .010 & .086 & .331 & .623 & .012 & .001 \\ & .125 & .201 & .956 & .926 & .265 & .827\end{array}$

Entry $(i, j)$ is the significance level of the F-test of the hypothesis that 4 lags of variable $i$ can be excluded from the regression predicting variable $j$. A low value indicates rejection of this hypothesis. 
Table 2. Correlation Matrix of Residuals

a. Log-levels, 1954:I - 1984:IV

$\begin{array}{rrrrrrr} & Y & P & G & B & M & \\ Y & 1.00 & & & & & \\ P & .13 & 1.00 & & & & \\ G & .41 & -.05 & 1.00 & & & \\ B & .07 & .15 & -.05 & 1.00 & 1.00 & 1.00 \\ M & .23 & .08 & .09 & .49 & .12 & \end{array}$

b. Log-differences, 1954:II - 1984:IV

$\begin{array}{lll}Y & P & G\end{array}$

1.00

.07

.04

$-.00$

$-.19$

.48
1.00

$-.08$

.01

$-.21$

.42
B

M

C

1.00

$-.27$

$-.44$

$-.51$
1.00

.48

.13
1.00

.34

1.00 

Table 3. Analysis of Dynamics Based on Standard Choleski Decomposition,
Log-levels, 1954:I - 1984:IV

a. Decomposition of the Variance of Output

Innovation

to

Quarter/

2

4

8

12

$\begin{array}{rrr}95.8 & 0.8 & 0.7 \\ 79.4 & 3.7 & 1.3 \\ 68.6 & 14.1 & 1.9 \\ 63.3 & 17.0 & 1.7\end{array}$

G

B

M

C

$\begin{array}{rrrr}.7 & 2.1 & 0.2 & 0.3 \\ .3 & 2.1 & 13.0 & 0.5 \\ .9 & 1.9 & 12.8 & 0.8 \\ .7 & 1.6 & 14.9 & 1.4\end{array}$

Entries show percentage of forecast variance of $Y$ at different horizons attributable to innovations in column variables. Ordering is as shown.

b. Response of Output to Innovations
Innovation $\quad \mathrm{Y}$
$\mathrm{P}$
G
B
M
C
to

Quarter/

$\begin{array}{rl}1.06 & .00 \\ .88 & -.13 \\ .70 & -.21 \\ .36 & -.24 \\ .32 & -.30 \\ .09 & -.33 \\ -.05 & -.35 \\ -.18 & -.31 \\ -.21 & -.28 \\ -.28 & -.25 \\ -.31 & -.25 \\ -. .32 & -.22\end{array}$

.00

$-.12$

.14

$-.08$

$-.12$

$-.13$

.00

$-.03$

9

10

11

12

$$
-.32
$$

$-.01$

$-.00$

.06

.07

$$
\begin{array}{r}
.00 \\
.20 \\
.16 \\
.02 \\
.04 \\
.06 \\
-.00 \\
.02 \\
.04 \\
.04 \\
.01 \\
.01
\end{array}
$$$$
.00
$$$$
.07
$$$$
.40
$$$$
.50
$$$$
.18
$$$$
-.08
$$$$
-.16
$$$$
-.12
$$$$
-.19
$$$$
-.21
$$$$
-.25
$$$$
-.24
$$

$-.08$

.09

.06

$-.03$

$-.06$

$-.06$

$-.08$

$-.11$

$-.11$

$-.10$

$-.09$

Entries show the dynamic response of $Y$ to a one-standard-deviation shock in each of the column variables. Quarter 1 is the fontemporaneous quarter. All entries are
multiplied by 10 . 
the .01 level by $M 1$, at slightly worse than the .01 level by defense spending, and, in the differenced case, at the .05 level by the GNP deflator. Neither the monetary base nor M1 are marginally predicted by any other variable. (It is surprising that $M 1$ is not predicted by the base.) In the differenced version, the base predicts the GNP deflator.

Table 3, which displays results for the log-level case only, is equally bad news for the credit hypothesis. ${ }^{22}$ For the ordering shown, shocks to prices and money explain most of the forecast variance of GNP not explained by shocks to GNP itself, at the four-, eight-, and twelve-quarter horizons. (These seem to me to be the correct horizons to use in a study of the effects of money on output, rather than the four-year horizon used in most other papers.) Similar results were obtained for the log-differenced case, and also when credit was put before money, or before money and the base, in the ordering of variables. In the impulse-response function shown in the bottom half of Table 3 , shocks to money are seen to have large effects on output during the first year especially (the entries in the table may be interpreted as elasticities), while the impact of credit shocks to output net nearly to zero during the first year and become negative thereafter. The only ray of hope for the credit hypothesis is in Table 2, which shows that the conditional contemporaneous correlation of credit with output is higher than that of any other variable with output, in both the level and differenced versions.

Thus the standard VAR method, as found by King, shows a strong dominance of money over credit, even when broader measures of credit are used. However, in Section II above I criticized the standard method, especially the variance

22 Table 3 is based on the Choleski decomposition of the variance matrix of residuals; that is, it assumes the standard recursive structure for the model $\mathrm{y}=\mathrm{By}+\mathrm{Au}$. 
decomposition and impulse-response exercises, because of their dependence on the assumption that the model relating the VAR innovations is recursive.

To test the dependence of the results on this assumption, I estimated the following illustrative model, in the form of (2.3). G, B, M, C, P, and Y below refer now to the innovations in each variable as estimated by the same VAR which underlies the results in Table 1-3. The model is:

$$
\begin{aligned}
& G=u_{1} \\
& B=\beta_{1} G+\beta_{2} M+\beta_{3} P+\beta_{4} Y+u_{2} \\
& C=\beta_{5} B+\beta_{6} P+\beta_{7} Y+u_{3} \\
& M=\beta_{8} B+\beta_{9} P+\beta_{10} Y+u_{4} \\
& P=\beta_{11} Y+u_{5} \\
& Y=\beta_{12} G+\beta_{13}(C-P)+\beta_{14}(M-P)+\alpha_{1} u_{5}+u_{6}
\end{aligned}
$$

Equations (3.1)-(3.6) are in the form $y=B y+A u$, where the $\beta^{\prime} s$ are elements of $B$ and $\alpha_{1}$ is the single non-diagonal element of $A$. As before, the "structural disturbances" $u$ are assumed to be uncorrelated; this assumption, admittedly strong, at least allows us to specify the elements of the B matrix in a relatively unrestricted way.

Equation (3.1) postulates that the innovation to military spending $G$ within a quarter is a structural disturbance; that is, it is not correlated with any of the other $u^{\prime} s$. Note that this assumption, which will be maintained throughout the paper, does not say that $G$ is uncorrelated with the other observable variables - B, C, M, etc; quite the contrary. (3.1) is also weaker than assuming exogeneity of military spending (total spending, not the VAR 
innovation), since it puts no restrictions on the behavior of the forecastable part of the variable.

(3.2) is the monetary authority's reaction function; the monetary base is permitted to respond within the current quarter to innovations in $G, M, P$, or Y. I do not allow the base to respond to innovations in credit, which I think is descriptively correct; however, the results are unchanged if money is treated symmetrically and is dropped from (3.2). (3.3) and (3.4) allow nominal credit and $M 1$ to respond endogenously to within-quarter innovations in the base, prices, or output. (3.5) is an aggregate supply curve, relating innovations in prices and output. (3.6) is a reduced form aggregate demand equation, which relates output to military spending (a major component of fiscal policy, chosen because it should be relatively exogenous) and which permits both shocks to real credit and shocks to real money to affect aggregate demand.

The six structural equations contain fourteen non-zero elements of the matrix $B$ to be estimated. Since I am able to estimate fifteen non-zero elements of $A$ and $B$ (plus the six variances of the u's) in a just-identified $6 \times 6$ system, I am free to specify one more parameter. I use this extra degree of freedom to add the term $\alpha_{1} u_{5}$ to (3.6); this has the effect of allowing a non-zero correlation between the disturbances to the model's two principal behavioral equations.

Equations (3.1)-(3.6) were jointly estimated by the methods described in Section II. The results for log-level data are in Table $4 a$, for log-differenced data in Table 4b. (It seemed important to estimate the model both ways, given recent controversies about the need for differencing time series models; see, e. g., Mankiw and Shapiro (1985). It is reassuring on this score that the two sets of estimates are quite similar. The similarity of the 
Table 4a. Estimated Money-Credit Model; Log-levels

(1) $\quad G=u_{1}$

(2) $\mathrm{B}=-\underset{(-0.87)}{.021 \mathrm{G}}+\underset{(0.11)}{.146 \mathrm{M}}+\underset{(1.35)}{.272 \mathrm{P}}+\underset{(0.17)}{.060 \mathrm{Y}}+\mathrm{u}_{2}$

(3) $\quad \mathrm{C}=-\underset{(-0.47)}{.060 \mathrm{~B}}+\underset{(2.18)}{.716 \mathrm{P}}+\underset{(0.81)}{.128 \mathrm{Y}}+\mathrm{u}_{3}$

(4) $\mathrm{M}=\underset{(0.27)}{.390 \mathrm{~B}}-\underset{(-0.08)}{.044 \mathrm{P}}+\underset{(1.55)}{.181 \mathrm{Y}}+\mathrm{u}_{4}$

(5) $P=-\underset{(-0.50)}{0.03 Y}+u_{5}$

(6) $\mathrm{Y}=\underset{(5.09)}{.127 \mathrm{G}}+\underset{(2.68)}{.439(\mathrm{C}-\mathrm{P})} \underset{(-0.27)}{.079(\mathrm{M}-\mathrm{P})}+\underset{(1.88)}{.849 \mathrm{u}_{5}}+\mathrm{u}_{6}$

$\sigma_{1}^{2}=\begin{gathered}1.08 \\ (7.87)\end{gathered} \quad \sigma_{2}^{2}=\underset{(0.92)}{.039} \quad \sigma_{3}^{2}=\underset{(5.04)}{.061}$

$\sigma_{4}^{2}=\frac{.042}{(2.33)}$

$\sigma_{5}^{2}=\frac{.009}{(6.09)}$

$\sigma_{6}^{2}=\frac{.068}{(3.91)}$

Data are in log-levels, quarterly, 1954:I - 1984:IV.

t-statistics are in parentheses. 
Table 4b. Estimated Money-Credit Model; Log-Differences
(1) $\quad G=u_{I}$
(2) $\mathrm{B}=-\underset{(-0.73)}{.018 \mathrm{G}}+\underset{(0.07)}{.104 \mathrm{M}}+\underset{(1.18)}{.269 \mathrm{P}}+\underset{(0.29)}{.122 \mathrm{Y}}+\mathrm{u}_{2}$
(3) $\quad \mathrm{C}=-\underset{(-1.15)}{.146 \mathrm{~B}}+\underset{(1.15)}{.435 \mathrm{P}}+\underset{(0.10)}{.019 \mathrm{Y}+\mathrm{u}_{3}}$
(4) $M=\underset{(0.33)}{.441 \mathrm{~B}}-\underset{(-0.24)}{.093 \mathrm{P}}+\underset{(1.37)}{.190 \mathrm{Y}+\mathrm{u}_{4}}$
(5) $\quad \mathrm{P}=\underset{(0.80)}{.059 \mathrm{Y}+\mathrm{u}_{5}}$
(6) $\mathrm{Y}=\underset{(4.41)}{.109 \mathrm{G}}+\underset{(2.17)}{.514(\mathrm{C}-\mathrm{P})}-\underset{(-0.41)}{.116(\mathrm{M}-\mathrm{P})}-\underset{(-0.01)}{.007} \mathrm{u}_{5}+\mathrm{u}_{6}$
$\sigma_{1}^{2}=\frac{1.12}{(7.84)}$
$\sigma_{2}^{2}=\frac{.046}{(0.95)}$
$\sigma_{3}^{2}=\frac{.066}{(4.09)}$
$\sigma_{4}^{2}=\frac{.042}{(3.38)}$
$\sigma_{5}^{2}=\frac{.008}{(7.57)}$
$\sigma_{6}^{2}=\frac{.082}{(5.53)}$

Data are in log differences, quarterly, 1954:II - 1984:IV.

t-statistics are parentheses 
results also reduces concern one might have about heteroskedasticity over time in the u's.)

A disappointing feature of the estimation outcome is that t-statistics are generally low; apparently there is a relatively large region of the parameter space which implies a covariance matrix for the VAR innovations similar to that found in the data. Nevertheless, there are some interesting results. For example, while money innovations are positively related to base innovations, as one would expect, credit is unrelated, if not negatively related, to the base (equations 3 and 4 ). This raises the possibility that open market operations are not particularly important for explaining changes in outstanding credit. Also, the within-quarter aggregate supply curve (equation 5) appears flat; there is little relation between innovations to $\mathrm{P}$ and innovations to $\mathrm{Y}$. Most striking, though, are the results for the aggregate demand equation (equation 6): Aggregate demand innovations within a quarter strongly depend on innovations in $G$ and in real credit; they do not depend at all, or depend negatively, on innovations to real money. While one should be very cautious in interpreting these estimates, they certainly do give some encouragement to the credit view. 23

The effect of orthogonalizing via the estimated model (instead of the recursive model/Choleski decomposition) on the results of the usual exercises is shown in Table 5. Results for the log-levels specification only are given. I use the expression "innovation to $X "$ as a short-hand for "innovation to the

The strong impact of credit in the aggregate demand equation was a robust finding. For example, (1) exclusion of post-1979 data, (2) exclusion of post-1973 data, and (3) exclusion of periods in which regulation $Q$ was binding all tended to raise the t-statistic on the credit variable, sometimes substantially. The result was also not affected by the use of nominal rather than real measures of money and credit. 
Table 5. Analysis of Dynamics Based on Estimated Money-Credit Model, Log-levels, 1954: I - 1984: IV

a. Decomposition of the Variance of Output

$\begin{array}{lcccccr}\begin{array}{c}\text { Innovation } \\ \text { to }\end{array} & Y & P & G & B & M & \text { C } \\ & 71.7 & 3.6 & 13.2 & 1.3 & 0.3 & 9.9 \\ & 58.9 & 3.0 & 14.5 & 1.1 & 11.7 & 10.9 \\ & 53.3 & 12.4 & 12.1 & 1.1 & 11.4 & 9.6 \\ & 46.4 & 18.4 & 10.4 & 1.3 & 13.1 & 10.5\end{array}$

Entries show percentage of forecast variance of $Y$ at different horizons attributable to innovations in estimated equations associated with each of the column variables.

b. Response of Output to Innovations

\begin{tabular}{|c|c|c|c|c|c|c|}
\hline & $Y$ & $\mathrm{P}$ & $G$ & B & M & $\mathrm{C}$ \\
\hline \multicolumn{7}{|c|}{ Quarter/ } \\
\hline 1 & .86 & .25 & .44 & -.04 & -.06 & .36 \\
\hline 2 & .83 & -.08 & .27 & -.16 & -.04 & .26 \\
\hline 3 & .55 & -.03 & .43 & -.07 & .38 & .32 \\
\hline 4 & .38 & -.15 & .10 & -.07 & .47 & .21 \\
\hline 5 & .39 & -.22 & .06 & -.00 & .16 & .12 \\
\hline 6 & .21 & -.30 & -.05 & -.06 & -.08 & -.02 \\
\hline 7 & -.04 & .36 & .02 & -.02 & -.17 & -.04 \\
\hline 8 & -.04 & -.35 & -.07 & -.04 & -.12 & -.10 \\
\hline 9 & -.08 & .32 & -.06 & -.07 & -.17 & -.15 \\
\hline 10 & -.15 & .31 & -.09 & -.09 & -.20 & -.17 \\
\hline 11 & -.20 & .31 & -.05 & -.06 & -.24 & -.18 \\
\hline 12 & -.22 & .29 & -.05 & -.06 & -.22 & -.18 \\
\hline
\end{tabular}

Entries show the dynamic response of $Y$ to a one-standard deviation shock in the estimated equations associated with each of the column variables. Quarter 1 is the contemporaneous quarter. All entries are multiplied by $10^{2}$. 
equation in Table $4 \mathrm{a}$ in which $\mathrm{X}$ is the dependent variable." Although this assignment of innovations to variables to some degree reflects only a normalization, it seems reasonable to treat, in particular, the innovations to equations (1)-(4) as representing "own shocks" (i.e., after elimination of the endogenous component) to $G, B, C$, and $M$ respectively. Note also that the results are independent of the ordering of the variables, which is not true in the standard case.

Table 5 looks rather different from Table 3 (which uses the standard decomposition). The contribution of "Y shocks" to the forecast error in $Y$ (output) is less--which makes sense, since "Y shocks" are now being interpreted primarily as aggregate demand shocks. Much of this difference is made up by the greater effect of military spending shocks. Most relevant to the present discussion, credit shocks (which were a minuscule part of forecast error in Table 3) now make about the same contribution to the variance of the forecast error in output as do M1 shocks.

In the IR functions, the effect of $M 1$ on output is found to be important in the third through fifth quarters, much as in Table 3. (Thus, although money shocks have little contemporaneous effect on output, they remain influential at a lag of six months to a year.) In strong contrast to Table 3 , however, in Table 5 credit shocks are found to have an immediate strong impact on output, with the effect lasting for a year or more.

This analysis suggests two conclusions. First, it appears that credit shocks are important for output, the inability of the standard VAR methodology to find this being due to its failure to separate correctly the "truly exogenous" component of credit $\left(\mathrm{u}_{3}\right)$ from its endogenous part. ${ }^{24}$ Second, the 
new estimates do not imply that the credit channel has replaced the monetary channel; instead, money and credit are parallel forces of approximately equal importance. Thus the puzzle of the monetary transmission mechanism remains.

A potentially important objection (suggested by the King-Plosser paper) can be made to the above conclusions, as follows: The model described by equations (3.1)-(3.6) allows for an endogenous response of money and credit to contemporaneous shocks in prices and output; however, it does not capture the possibility that money and credit may also respond to new information (information not fully described as a function of shocks to current variables) which agents have about future prices and output. Under this interpretation, the disturbances from equations (3.3) and (3.4) are better thought of as measuring this new information, rather than as exogenous shocks to credit and money. It would thus not be surprising that these estimated disturbances help forecast output.

It is probably hopeless, in general, to try to use time series methods (and no further information) to distinguish the hypothesis "X causes $\mathrm{Y}^{\prime \prime}$ from the hypothesis "Y is exogenous, and $\mathrm{X}$ moves in anticipation of movements in $\mathrm{Y}$." Fortunately, recent work on real business cycles suggests some more specific, and perhaps testable, models. These are considered in the next section.

\section{Real Business Cycles: Money versus Interest Rates}

Some very interesting recent papers (see especially Black (1982), Kydland and Prescott (1982), and Long and Plosser (1983)) have focused attention on the idea of "real business cycles." Real business cycle theory is an attempt to show that the principal features of cycles (persistence, patterns of comovement) can be adequately modelled in a framework of dynamic, competitive general equilibrium, in which all shocks are taken to be "real" (i.e., to 
tastes or technology). In particular, this approach denies that nominal shocks, e. g., to the money supply, are of any significance in the determination of real fluctuations. 25

Obviously, an important element of the real business cycle research program is to reconcile the claim that nominal shocks don't matter with the empirically observed correlations of real and nominal magnitudes--correlations that are not predicted, for example, by the traditional classical model. From a theoretical perspective, the best-known recent attempt to achieve this reconciliation is the previously mentioned work by $R$. King and Plosser. Following early antecedents such as Tobin (1971) and Black (1972); King and Plosser argue that the money-output correlation reflects purely endogenous changes in money holdings, made in response to changes in current or expected future output. Although some points of their analysis could be criticized (e. g., there is no tight explanation of the relation between transaction services and the level of demand deposits, and the model does not yield a very strong prediction of price procyclicality) the overall framework is not implausible.

What is the evidence for the real business cycle (hereafter, RBC) view of the money-income correlation? King and Plosser document one important fact, noted earlier by Stephen King (1982), in showing that income is much more strongly correlated with inside money, or the money multiplier, than with outside or base money. This is clearly encouraging for real business cycles. There are some caveats: First, King and Plosser do find a small degree of correlation between the base and output. Second, in general it should be shocks from a model dominated by real propagation mechanisms. Kydland (1983) integrates the two approaches. 
recognized that the lack of correlation does not rule out a causal link. For example, if the Fed is attempting to use the base to stabilize the economy, this may complicate the interpretation of the time series relationship between the base and output. 26

A second piece of favorable evidence, to which I will give a good deal of attention, was documented by Sims (1980b), following some earlier work by Mehra (1978). Using monthly data, Sims showed that the addition of a short-term nominal interest rate (the rate on 4-6 month prime commercial paper) to a VAR system also including industrial production, wholesale prices, and M1, had the effect of virtually eliminating the marginal predictive power of money for output (i.e., industrial production), at least for the postwar period. ${ }^{27}$ The interest rate, in contrast, has significant predictive power for output in the four-variable system, a positive innovation in interest rates being followed about six months later by a smooth decline in output.

Sims' own interpretation of this finding was in the spirit of the RBC approach. His theory is that interest rate innovations reflect primarily new information about future profitability. A decline in expected future

An example, based on a comment in Sims (1972), is as follows: Assume a pure monetarist model, where output depends on inside money and a forecastable error, and where money depends on the base plus a forecastable error. The base is set one period in advance. If the base is set to minimize the variance of output, then output and inside money will be correlated with each other, but both output and inside money will be uncorrelated with current and lagged values of the base. (However, output and inside money will predict future values of the base.) With imperfect optimization or partial endogeneity of the base, the time series relation of output and the base could be complex. See Buiter (1984) for an extensive analysis. sample. Because of the importance of financial panics and international capital movements during the interwar, Sims argued, however, that this finding has little relevance for contemporary macroeconomic analysis. 
profitability, given current profitability, lowers the prices of capital assets and raises current yields. If people are on average correct in their expectations, then an innovation to interest rates will be followed sometime later by a decline in the economy, as found in the data. The behavior of the money stock reflects a fall in money demand in anticipation of lower output, as in the King-Plosser story. The leading behavior of interest rates (and money, in a three-variable system) are expectational, not causa1, phenomena. ${ }^{28}$

A recent paper by Litterman and Weiss (1985) reinterprets the Sims finding somewhat, but in a way also consistent with the RBC approach. Litterman and Weiss present evidence that (1) the real interest rate is exogenous, i.e., it evolves without feedback from other macro variables, and (2) the important part of the nominal interest rate, for the purposes of forecasting output, is the expected inflation component, not the real interest rate component. As in the Sims example, interest rates here lead output not for any causal reason but because interest rates embody information currently available to the public about future output movements. (In the specific model presented by Litterman and Weiss, the negative relationship between nominal interest rates and future output arises because lower future output leads, via the money demand function and given the money supply process, to higher future prices and higher expected inflation today.)

These findings suggest ${ }^{29}$ a particular variant of the RBC explanation of the money-income relation: I.e, that not only is the lead relation of money to output due simply to the response of money demand to new information about

A closely related and somewhat more formal analysis of the role of interest rates in the explanation of money-income-price correlations is contained in King and Plosser.

But see McCa1lum (1983) for an opposing view. 
future output; but that all of this new information is contained in nominal interest rates. The evidence of Sims and of Litterman-Weiss favors this view; below, I use the alternative VAR methodology of this paper to reconsider it. First, though, I present some evidence from the standard VAR approach.

Evidence. Tables 6 through 8 give the results of a standard Sims-type analysis of a six-variable system including real GNP ( $Y$ ), the GNP deflator (P), military spending (G), the monetary base (B), the Ml measure of the money supply (M), and the (end-of-quarter, prospective) nominal return on three-month Treasury bills, as in Huizinga and Mishkin (1984) (R). This is the same as the system studied in Section II, with the interest rate replacing the credit measure. As before, I estimate one set of equations in log-levels (with a constant and trend term) and a second in log-differences (with a constant). Due to data availability, here the last quarter in the sample is 1984:III. Most noteworthy about my results is that I do not obtain the outcome that inclusion of the nominal interest rate eliminates the predictive power of money for output. In Table 6, interest rates appear to forecast money and prices well; but the F-statistic for the hypothesis that interest rates marginally predict output is lower than the corresponding statistic for every variable except prices in the log-level specification, and for every variable in the log-differences specification. In particular, money predicts output at the .01 significance level in both specifications.

The variance decomposition exercise for output (Table 8a), which uses the standard Choleski decomposition, tells a similar story. While base shocks do not appear important, money shocks explain a significant fraction of the forecast variance of output at the 4-, 8-, and 12-quarter horizons. Interest rate shocks explain relatively less. (The relative contributions of $M$ and $R$ shocks to the variance of $Y$ are the same if $M$ and $R$ are interchanged in the 
Table 6. Tests of Marginal Predictive Power of Row Variables for Column Variables

a. Log-leve1s, 1954:I - 1984:III

$\begin{array}{ccccccc} & \mathrm{Y} & \mathrm{P} & \mathrm{G} & \mathrm{B} & \mathrm{M} & \mathrm{R} \\ \mathrm{Y} & .000 & .787 & .437 & .169 & .141 & .019 \\ \mathrm{P} & .618 & .000 & .409 & .856 & .566 & .001 \\ \mathrm{G} & .021 & .067 & .000 & .697 & .409 & .507 \\ \mathrm{~B} & .068 & .190 & .470 & .000 & .889 & .003 \\ \mathrm{M} & .007 & .407 & .237 & .305 & .000 & .004 \\ \mathrm{R} & .078 & .021 & .844 & .290 & .001 & .000\end{array}$

b. Log-differences, 1954:II - 1984:III

$\begin{array}{ccccccc} & \mathrm{Y} & \mathrm{P} & \mathrm{G} & \mathrm{B} & \mathrm{M} & \mathrm{R} \\ \mathrm{Y} & .001 & .107 & .293 & .488 & .374 & .038 \\ \mathrm{P} & .004 & .000 & .270 & .916 & .939 & .008 \\ \mathrm{G} & .005 & .117 & .000 & .934 & .477 & .788 \\ \mathrm{~B} & .021 & .062 & .897 & .006 & .705 & .068 \\ \mathrm{M} & .003 & .526 & .132 & .342 & .000 & .002 \\ \mathrm{R} & .952 & .001 & .425 & .211 & .000 & .000\end{array}$

Entry $(i, j)$ is the significance level of the F-test of the hypothesis that 4 lags of variable $i$ can be excluded from the regression predicting variable $j$. A low value indicates rejection of this hypothesis. 
Table 7. Correlation Matrix of Residuals

a. Log-levels, 1954: I - 1984:III

$\begin{array}{rrrrrrr} & Y & P & G & B & M & R \\ Y & 1.00 & & & & & \\ P & .11 & 1.00 & .00 & 1.00 & & \\ \text { G } & .39 & .22 & -.05 & 1.00 & 1.00 & \\ B & .10 & .25 & .03 & .50 & .17 & 1.00 \\ M & .34 & .12 & .16 & .08 & \end{array}$

b. Log-differences, 1954:II - 1984:III

$\mathrm{Y}$

$\mathrm{P}$

G

1.00

.14

.27

.08

.27

.29

1.00
-.01
.16
.24
.11

1.00

.01

.05

.09

24
B

M

R
1.00

.56

.10
1.00

.21
1.00 
Table 8. Analysis of Dynamics Based on Standard Choleski Decomposition, Log-levels, 1954: I - 1984:III

a. Decomposition of the Variance of Output

\begin{tabular}{|c|c|c|c|c|c|c|}
\hline & $Y$ & $P$ & G & B & M & $\mathbf{R}$ \\
\hline \multicolumn{7}{|c|}{ Quarter/ } \\
\hline 2 & 96.1 & 0.2 & 0.8 & 1.1 & 0.3 & 1.5 \\
\hline 4 & 82.4 & 0.5 & 1.9 & 1.2 & 11.6 & 2.4 \\
\hline 8 & 63.8 & 10.9 & 2.2 & 1.1 & 12.1 & 9.9 \\
\hline 12 & 54.6 & 16.3 & 2.2 & 0.9 & 15.1 & 10.9 \\
\hline
\end{tabular}

Entries show percentage of forecast variance of $\mathrm{Y}$ at different horizons attributable to innovations in column variables. Ordering is as shown.

b. Response of Output to Innovations

\begin{tabular}{|c|c|c|c|c|c|c|}
\hline $\begin{array}{c}\text { Innovation } \\
\text { to }\end{array}$ & $\mathrm{Y}$ & $\mathbf{P}$ & G & B & $M$ & $R$ \\
\hline & 1.05 & .00 & .00 & .00 & .00 & .00 \\
\hline & .83 & -.06 & -.12 & .14 & .07 & .17 \\
\hline & .66 & -.06 & .07 & .03 & .39 & .08 \\
\hline & .36 & -.08 & -.19 & -.11 & .42 & -.18 \\
\hline & .31 & -.23 & -.14 & -.08 & .16 & -.37 \\
\hline & .12 & -.32 & -.09 & .02 & -.04 & -.29 \\
\hline & .03 & -.38 & .04 & -.03 & -.23 & -.21 \\
\hline & -.10 & -.33 & .03 & -.01 & -.24 & -.22 \\
\hline & -.16 & -.32 & .09 & .01 & -.24 & -.25 \\
\hline & -.22 & -.32 & .05 & .04 & -.23 & -.19 \\
\hline & -.24 & -.32 & .09 & .03 & -.29 & -.18 \\
\hline & -.30 & -.28 & .08 & .04 & -.28 & .15 \\
\hline
\end{tabular}

Entries show the dynamic response of $Y$ to a one-standard-deviation shock in each of the column variables. Quarter 1 is the contemporaneous quarter. All entries are multiplied by $10^{2}$. 
ordering.) In the estimated impulse-response patterns (Table $8 \mathrm{~b}$ ), money shocks are followed by relatively large output changes of the same sign at the 3- to 5-quarter horizon. The response of output to an interest rate shock exhibits a pattern similar to that found by Sims and by Litterman and Weiss.

The reason that $I$ failed to obtain the result that inclusion of nominal interest rates eliminates the effect of money on output, it turns out, is that I included a trend term, while the previous authors did not. ${ }^{30}$ As S. King (1982) and Runkle (1985) have already noted, adding a trend significantly enhances the estimated role for money in predicting output. This was clearly the case in my data. ${ }^{31}$ Since $I$ put in the trend term in the first place in the hope of minimizing conditional heteroskedasticity (which is particularly problematic for my estimation method), and since I know of no compelling theoretical argument to take it out, I retain the trend in the principal estimates reported below. However, I also discuss the effects of eliminating the trend.

The above results follow from the standard VAR approach. As was shown in the previous section, however, the interpretation of VARs through a structural

The principal results of both Sims and Litterman-Weiss are obtained from VARs using data in log-levels and including a constant, but no trend. Litterman and Weiss also report the effect of adding trend and trend-squared (footnote 4, p. 132). Although they characterize this as leaving their decomposition results "essentially unchanged", the percentage of output variance explained by M1 at 24 quarters rises from $7.2 \%$ to $19.4 \%$.

With no trend, standard analysis of my six-variable system ascribes $46 \%$ of the variance of output at twelve quarters to interest rate shocks, and only $6 \%$ of this variance to money shocks. This is similar to the Sims/Litterman-Weiss finding. More favorable, among the no-trend results, to the view that money matters are that: 1) At four quarters, money explains $10 \%$ of the forecast variance of output, to a bit over $4 \%$ for interest rates. 2) The marginal predictive power of money for output is significant at the .006 level, compared to the .040 level for interest rates. 
model of the innovations (the Blanchard-Watson methodology) can give appreciably different results from the standard approach. To explore this in the present case, I used the methods described above to estimate the following "real business cycle" model, suggested by a similar model in titterman-Weiss. As in the model in Section III, G, B, R, M, P, and $Y$ are now the innovations from a first-stage VAR (in log-levels) of a system including military spending, the monetary base, the nominal 3-month treasury bill interest rate, the M1 money stock, the GNP deflator, and real GNP (plus constant and trend). Suppressing the time subscripts, I write the model as:

$$
G=u_{1}
$$

$$
B=B_{1} G+\beta_{2} R+\beta_{3} M+\beta_{4} P+\beta_{5} Y+u_{2}
$$

$$
R=\left(\hat{P} e^{e}\right)+\beta_{6} G+u_{3}+\alpha_{1} u_{6}
$$

$$
M=\beta_{7} B+\beta_{8} R+\beta_{9} P+\beta_{10} Y+u_{4}
$$

$$
P=\beta_{11} R+1.0 M+\beta_{12} Y+u_{5}
$$

$$
Y=\beta_{13} G+\alpha_{2} u_{5}+u_{6}
$$

Equations (4.1)-(4.6) require some explanation. Equation (4.1) says that innovations to military spending are not caused by innovations to other variables within the quarter, as before. (4.2) is a policy reaction function that relates innovations in the base to innovations in all the other variables; $\mathrm{u}_{2}$ is the "own shock" to the base. 
Equation (4.3), which specifies how the innovation to the nominal interest rate is determined, is important for the interpretation of the model.

To motivate (4.3), write the innovation to (the log of one plus) the nominal interest rate, $R_{t}$, as

$$
\text { (4.7) } \quad R_{t} \equiv r_{t}+\left(P_{t}^{e}-P_{t}\right)
$$

where $r_{t}$ is the innovation to (the log of one plus) the real interest and $P_{t}$ is the innovation to (the log of) the price level. $\mathrm{P}_{t}^{e}$ is the innovation, between $t-1$ and $t$, in the expectation of the $\log$ of the price level as of $t+1$.

Now decompose $\mathrm{P}_{t}^{\mathrm{e}}$ as

$$
\text { (4.8) } \quad \mathrm{P}_{\mathrm{t}}^{\mathrm{e}} \equiv \hat{\mathrm{P}}_{\mathrm{t}}^{\mathrm{e}}+\mathrm{v}_{\mathrm{t}}
$$

where $\hat{\mathrm{P}}_{t}^{e}$ is the innovation to the expectation of the price level in $t+1$ knowable given only the variables in the VAR at time $t$, while $v_{t}$ represents all additional new information about $P_{t+1}$ available to agents $t$. Note that the series $\hat{\mathrm{P}}_{t}^{e}$ is directly computable using the first-stage prediction equation for $P$; it is just the estimated coefficient on the first lag of each of the right-hand-side variables times the innovations to each of these variables in t. Thus (4.8) breaks up the innovation in the expected price level into a part observable by the econometrician and a part that is unobservable.

Next. we must model the process generating the real interest rate innovation, $r_{t}$. One possibility would be to follow Litterman-Weiss exactly, and to treat $r_{t}$ as strictly autonomous, i.e., we could write

$$
r_{t}=w_{t}
$$


where $w_{t}$ is a white noise process uncorrelated with any of the other structural disturbances in $t$. Equation (4.3) could then be written

$$
(4.3)^{-} \quad R=\left(\hat{P} \hat{e}^{e}-P\right)+u_{3}
$$

where

$$
u_{3 t} \equiv v_{t}+w_{t}
$$

Rather than adopt (4.3)', however, I allow for the possibility that contemporaneous real shocks might influence the real interest rate innovation. $^{32}$ Specifically, I assume

$$
r=\beta_{6} G+\alpha_{1} u_{6}+w
$$

thus shocks to real military spending $(G)$ and to real output ( $u_{6}$, see below), are allowed to affect $r$, as well as the own shock w. Together with (4.7) and (4.8), (4.11) implies (4.3), with $u_{3}$ still defined as in (4.10). Note that, as $G$ and $u_{6}$ are both primitive real shocks, uncorrelated with other disturbances, (4.3) embodies the critical Litterman-Weiss property that the real interest rate innovation is independent of any nominal disturbance. Note also that, under the variant of the RBC model being considered, the disturbance $u_{3}$ in (4.3) should embody a great deal of information about future output. Indeed, under the strongest form of the Sims/Litterman-Weiss hypothesis, given $u_{3}$ and including ( 4.1 ), adding (4.3) would violate the rank condition for identification. 
all real disturbances, nominal disturbances should have no additional predictive power for real output. 33

To complete the model specification: (4.4) is a money supply equation that allows the quantity of $M 1$ to depend on the base, interest rates, prices, output, and an own shock $u_{4} \cdot(4.5)$ is the money market equilibrium equation written with $P$ on the left-hand side. (4.6) is a reduced-form equation for real output. The term $\alpha_{2} u_{5}$ in (4.6) allows (analogously to the previous section) for a non-zero covariance between errors to the money market equilibrium and output equations. ${ }^{34}$ ( $I$ allow output to depend on the money demand shock in order to give the model a better chance to fit the data, and because, given the King-Plosser framework, money demand shocks may properly be thought of as shocks to tastes or technology, i.e., real shocks.)

Equations (4.1)-(4.6), it should be repeated, form a real business cycle mode1, with these features: The real interest rate innovation depends only on real shocks (to military spending and to real output) and an own shock.

Expected inflation, which forms part of the nominal interest rate, depends in part on new information not observable by the econometrician. Real output innovations depend on shocks to military spending and to money demand, and on an own shock. The price level adjusts flexibly to balance money supply and money demand, given output and nominal interest rates. Last, but very important, in this model the correlations of innovations in inside money and

It would be interesting from this point of view to break up the predictive power of $u_{3}$ into that attributable to $v_{t}$ and that attributable to $w_{t}$. Unfortunately this decomposition is not identified.

34 The real interest rate should appear in (4.6). However, given that we cannot isolate the real and expected-inflation components of the composite disturbance $u_{3}$, the coefficient of the real rate $(4.6)$ is not identifiable. The other estimated coefficients in (4.6) should be interpreted as reflecting this specification bias. 
the base with those in real output are explained entirely by the endogenous response of $M$ and $B$ to output, prices, and interest rates; the own shocks to the base and to money, $u_{2}$ and $u_{4}$, have zero contemporaneous effect on output or real interest rates.

Estimates of the model for the log-level specification are given in Table $9 \mathrm{a}$, for the log-differenced specification in Table 9b. The results are similar in the two specifications and are on the whole reasonable, although again standard errors are large. Interest rates appear to be influenced positively both by military spending and, rather strongly, by real output shocks. Output depends positively on military spending and negatively on shocks to the price determination equation. The base reaction function is very imprecisely estimated; inside money depends primarily on the base and, to a lesser extent, on output.

The money market equilibrium equation is estimated imprecisely, and with the wrong sign for the nominal interest rate. Interestingly, when I tried estimating the system using the beginning-of-quarter rather than the (theoretically correct) end-of-quarter interest rate, this equation was estimated with the right signs and high t-statistics. No subsequent conclusions were affected by the use of alternative timing convention, however.

I also estimated the real business cycle model dropping first post-1979, then post-1973 data. The qualitative features of the estimates and of the implied dynamics were not much changed.

An analysis of the system's dynamics, interpreted via the structural model in Table 9a rather than by an assumed recursive structure, is given in Table 10. Again, "innovation to $X "$ is short-hand for "innovation to the error term corresponding to the equation for which $X$ is the dependent variable." 
Table 9a. Estimated Real Business Cycle Model; Log-levels

(1) $\quad G=u_{1}$

(2) $\mathrm{B}=\underset{(-0.51)}{-.029 \mathrm{G}}+\underset{(0.13)}{.011 \mathrm{R}}+\underset{(0.16)}{.130 \mathrm{M}}-\underset{(-0.41)}{2.93 \mathrm{P}}+\underset{(0.32)}{.154 \mathrm{Y}}+\mathrm{u}_{2}$

(3) $\quad \mathrm{R}=(\hat{\mathrm{P}}-\mathrm{P})+\underset{(1.85)}{.036 \mathrm{G}}+\mathrm{u}_{3}+\underset{(3.54)}{.277} \mathrm{u}_{6}$

(4) $M=\underset{(2.16)}{1.65 \mathrm{~B}}-\underset{(-0.14)}{.019 \mathrm{R}}-\underset{(-0.70)}{2.18 \mathrm{P}}+\underset{(0.97)}{.187 \mathrm{Y}}+\mathrm{u}_{4}$

(5) $\quad \mathrm{P}=\underset{(-1.14)}{-.131 \mathrm{R}}+1.0 \mathrm{M}-\underset{(-0.01)}{.002 \mathrm{Y}}+\mathrm{u}_{5}$

(6) $Y=\underset{(4.70)}{.123 G}-\underset{(-1.60)^{5}}{.383 u_{5}}+u_{6}$
$\sigma_{1}^{2}=\frac{1.10}{(7.84)}$
$\sigma_{2}^{2}=\frac{.127}{(0.30)}$
$\sigma_{3}^{2}=\frac{.044}{(7.41)}$
$\sigma_{4}^{2}=\frac{.118}{(2.56)}$
$\sigma_{5}^{2}=\underset{(5.37)}{.045}$
$\sigma_{6}^{2}=\frac{.086}{(5.34)}$

Data are in log-levels, quarterly, 1954:I - 1984:III. $t$-statistics are in parentheses. 
Table 9b. Estimated Rea1 Business Cycle Mode1; Log-differences.

(1) $\quad G=u_{1}$

(2) $\mathrm{B}=\underset{(-0.10)}{.080 \mathrm{G}}+\underset{(-0.10)}{-1.64 \mathrm{R}}+\underset{(0.14)}{2.11 \mathrm{M}}+\underset{(0.10)}{13.8 \mathrm{P}}-\underset{(-0.11)}{.051 \mathrm{Y}}+\mathrm{u}_{2}$

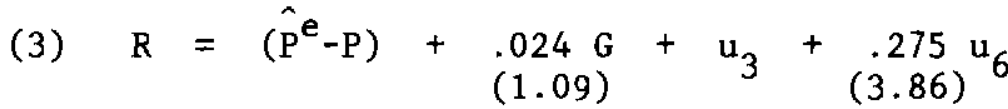

(4) $M=\underset{(1.76)}{1.75} \mathrm{~B}+\underset{(-0.09)}{-.055 \mathrm{R}}+\underset{(0.07)}{.343 \mathrm{P}}+\underset{(0.50)}{.080 \mathrm{Y}}+\underset{\mathrm{u}}{(0.09}$

(5) $\quad \mathrm{P}=\underset{(-0.35)}{-.044 \mathrm{R}}+1.0 \mathrm{M}-\underset{(-0.47)}{.011 \mathrm{Y}}+\mathrm{u}_{5}$

(6) $Y=\underset{(3.11)}{.087}-\underset{(-0.09)}{.045} \mathrm{u}_{5}+\mathrm{u}_{6}$

$\begin{array}{lll}\sigma_{1}^{2}=\underset{(7.81)}{1.06} & \sigma_{2}^{2}=\underset{(0.05)}{1.82} & \sigma_{3}^{2}=\begin{array}{r}.058 \\ (8.00)\end{array} \\ \sigma_{4}^{2}=\underset{(0.65)}{.113} & \sigma_{5}^{2}=\underset{(7.97)}{.044} & \sigma_{6}^{2}=\underset{(7.51)}{.101}\end{array}$

Data are in log-differences, quarterly, 1954:II - 1984:III. t-statistics are in parentheses. 
Table 10. Analysis of Dynamics Based on Estimated Real Business Cycle Model, Log-levels, 1954: I - 1984:III

a. Decomposition of the Variance of Output

\begin{tabular}{|c|c|c|c|c|c|c|}
\hline \multirow{2}{*}{\multicolumn{7}{|c|}{$\begin{array}{l}\text { Innovation } \mathrm{Y} \\
\text { to } \\
\text { Quarter/ }\end{array}$}} \\
\hline & & & & & & \\
\hline 2 & 76.8 & 9.2 & 11.5 & 0.0 & 0.5 & 1.9 \\
\hline 4 & 60.7 & 21.4 & 11.2 & 1.0 & 3.3 & 2.5 \\
\hline 8 & 47.0 & 19.0 & 8.4 & 8.5 & 7.5 & 9.7 \\
\hline 12 & 40.6 & 17.4 & 6.6 & 10.6 & 13.6 & 11.2 \\
\hline
\end{tabular}

Entries show percentage of forecast variance of $\mathrm{Y}$ at different horizons attributable to innovations in estimated equations associated with each of the column variables.

b. Response of Output to Innovations

\begin{tabular}{|c|c|c|c|c|c|c|}
\hline $\begin{array}{l}\text { Innovation } \\
\text { to } \\
\text { cter/ }\end{array}$ & $\mathrm{Y}$ & $\mathrm{P}$ & G & B & M & $\mathrm{R}$ \\
\hline & .93 & -.26 & .41 & .00 & .00 & .00 \\
\hline & .75 & -.32 & .21 & .01 & -.10 & .19 \\
\hline & .46 & -.48 & .32 & -.06 & .14 & .13 \\
\hline & .30 & -.45 & -.03 & -.16 & .25 & -.13 \\
\hline & .27 & -.29 & -.00 & -.24 & .02 & -.34 \\
\hline & .11 & -.13 & -.02 & -.26 & -.20 & -.28 \\
\hline & .03 & .08 & .06 & -.32 & -.28 & -.22 \\
\hline & -.08 & .13 & -.00 & -.26 & -.28 & -.24 \\
\hline & -.15 & .14 & .03 & -.24 & -.29 & -.26 \\
\hline & -.20 & .14 & -.02 & -.23 & -.30 & -.20 \\
\hline & -.22 & .20 & -.00 & -.23 & -.33 & -.20 \\
\hline & -.27 & .21 & -.03 & -.19 & -.31 & -.17 \\
\hline
\end{tabular}

Studies show the dynamics response of $\mathrm{Y}$ to a one-standard deviation shock in the estimated equations associated with each of the column varjables. Quarter 1 is the contemporaneous quarter. All entries are multiplied by $10^{2}$. 
There are a number of interesting differences between Table 10 and Table 8, which uses the standard decomposition; e.g., the results in Table 10 give military spending a bigger role in determining output. However, for assessing the variant of the $\mathrm{RBC}$ hypothesis under consideration, the most important findings concern the effects of base and inside money shocks on output. Recall that, as the model is estimated, base and money shocks are measured net of any contemporaneous endogenous response to prices or output; moreover, by construction, the own shocks to the base and the money $\left(u_{2}, u_{4}\right)$ are orthogonal to the nominal interest rate disturbance $\left(u_{3}\right)$. The real business cycle hypothesis would therefore predict that the constructed money and base shocks should not contribute to the forecast variance of real output. In fact, they do: at the 8-quarter horizon $u_{2}$ and $u_{4}$ explain a total of $16.0 \%$ of the variance of the forecast error for output, and they explain $24.2 \%$ of the variance at twelve quarters. (The corresponding percentages for the nominal interest rate shock, $u_{3}$, are $9.7 \%$ and $11.2 \%$ ) Moreover, the explanatory power of shocks to the base is similar to that of shocks to money, in contrast to the result in Table 8 .

The dynamic response of output to base and money shocks (Table 10b) weakens the case for money a bit: M1 shocks still positively affect output at the 3-4 quarter horizon, but the effect is less pronounced than in Table 8 . Base shocks have a primarily negative effect on output, after a small short-run positive effect. (The effect of base shocks on output might be explainable in a combined monetarist-RBC model in which the authorities manipulate the base to try to dampen expected future output changes.)

For comparison, I also did the above analysis for the no-trend case. (Recall that omitting the trend produced much more favorable results to the $\mathrm{RBC}$ hypothesis in the standard VAR analysis.) The implied contemporaneous 
correlations of the residuals, and thus the estimated model, were very similar to the with-trend case, and so are not reported. However, the dynamic analysis looked rather different (see Table 11).

With no trend, the results are very much like what was found by Sims and Litterman-Weiss (even though here the orthogonalization of the VAR residuals was done via an estimated structural model). Most striking is the finding that interest rate innovations explain $47.0 \%$ of the variance of output at twelve quarters, compared to $1.7 \%$ for $M 1$. (The base does a little better than M1, explaining $7.7 \%$ of the output variance at twelve quarters.)

Even in this best case for the RBC hypothesis, however, I think some argument can be made for a role for money. Looking at the impulse-response functions, one can see that M1 shocks still have an important effect on output at the 3- to 5-quarter horizon. The reason for the dominance of interest rate shocks at longer horizons appears to be that the effects of interest rate shocks are "permanent", while the effects of money on output are estimated to die away quickly. But the transitory nature of the real effects of monetary shocks does not contradict the received view that money works through temporary real-nominal confusion. We might imagine, therefore, that money shocks are a source of temporary aggregate demand variation, while interest rate shocks signal future productivity changes, which are essentially permanent. (The response of output to its own shock in Table $11 \mathrm{~b}$ seems quite consistent with the view that real shocks are largely permanent.) This allows some scope for money, while acknowledging that the real shocks emphasized in RBC models may be extremely important.

Overall, the particular variant of the $R B C$ we have been considering does not appear to fit the facts completely. Again, this does not rule out a less restrictive $\mathrm{RBC}$ model in which the own shocks to base money and $M 1$ also are 
Table 11. Analysis of Dynamics Based on Estimated Real Business Cycle Model, Log-levels, 1954:I - 1984:III; no trend.

a. Decomposition of the Variance of Output

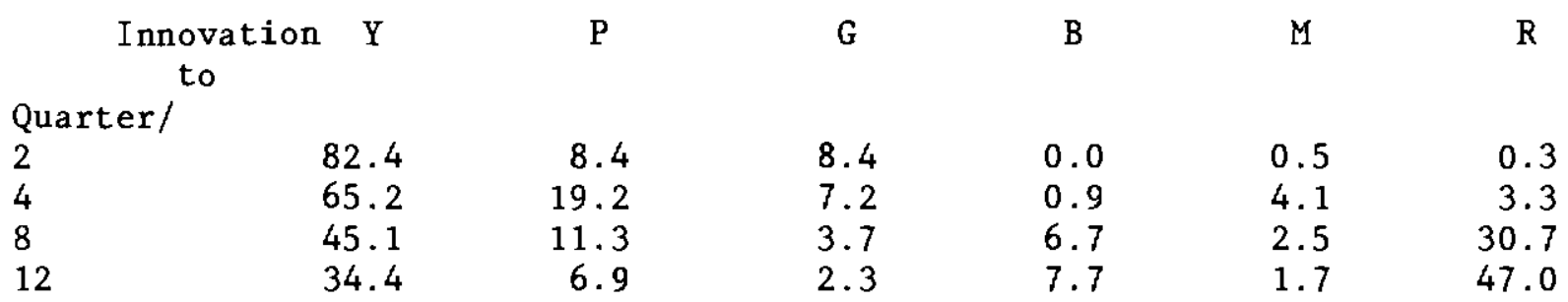

Entries show percentage of forecast variance of $\mathrm{Y}$ at different horizons attributable to innovations in estimated equations associated with each of the column variables.

b. Response of Output to Innovations

Innovation

to

$$
\text { Quarter/ }
$$

2

3

4

5

6

7

8

9

10

11

12
P G

$-.24$

$-.33$

$-.51$

$-.48$

$-.34$

$-.20$

$-.02$

$-.01$

$-.01$

$-.01$

.04

.06
B

.37

.17

.26

$-.10$

$-.06$

$-.10$

$-.03$

$-.08$

$-.02$

$-.05$

$-.02$

$-.05$
.00

$-.00$

$-.07$

$-.17$

$-.28$

$-.31$

$-.39$

$-.35$

$-.34$

$-.32$

$-.33$

$-.30$
M

.00

$-.10$

.18

.31

.10

$-.10$

$-.13$

$-.08$

$-.07$

$-.08$

$-.06$

$-.05$
R

.00

.08

$-.03$

$-.33$

$-.63$

$-.70$

$-.73$

$-.81$

$-.89$

$-.88$

$-.92$

$-.94$

Studies show the dynamics response of $\mathrm{Y}$ to a one-standard deviation shock in the estimated equations associated with each of the column variables. Quarter 1 is the contemporaneous quarter. All entries are multiplied by $10^{2}$. 
interpreted as reflecting information about future output, independent of that found in nominal interest rates. However, such a model is difficult to distinguish without further information from a "money matters" model, and I do not attempt it here.

\section{Conclusion}

This paper has used an alternative VAR methodology, based on work of Blanchard and Watson, consider two alternative explanations of the money-income correlation: the "credit view" and a variant of the real business cycle hypothesis. The two alternatives are treated asymetrically, since the hypotheses considered are (1) that credit shocks explain nothing and (2) that real effects explain everything. Evidence is found against both hypotheses (although in case (2) the strength of the evidence depends a great deal on one's views about the use of trends). It seems likely that a complete macro model must allow for all three sorts of influences--credit market, real, and monetary--in order to explain the data. For policy-makers, the conservative course is to continue to use care to avoid destabilizing shocks to credit markets and to the money supply.

Because the methodology is relatively untested and because there is room for disagreement about model specification, the results of this paper about specific hypotheses should be considered tentative. The paper does demonstrate, however, that the structural interpretation of VARs can be very sensitive to the model that one assumes (implicitly or explicitly) is relating contemporaneous residuals. Further applications of the VAR methodology should take this into account. 


\section{Data Appendix}

Data are quarterly, seasona1ly adjusted, and cover the period 1953:I to 1984:IV (except for the interest rate, which was available up to 1984:III). As described in the text, in the estimation all variables were in $\log -1$ evel or log-differenced form.

Rea1 GNP (Y), the GNP price deflator (P), and real defense spending $(G)$ are from NIPA. The M1 money stock (M) and the monetary base (B) series for 1959:I on were provided by the Federal Reserve; M corresponds to the average M1 stock over the last month of the quarter, B to the monetary base recorded during the last week of the quarter. For $1953: \mathrm{I}$ to $1958: \mathrm{IV}$, the quarterly series for M1 and the monetary base from Banking and Monetary Statistics were spliced to the post-1958 series. The credit variable (C) is the sum of commercial bank loans, mortgages held by S\&Ls, and mortgages plus "other loans" held by mutual savings banks, a11 for the last month of the quarter and al1 from the Federal Reserve Bulletin. The nominal interest rate ( $R$ ) is the three-month prospective Treasury bill rate at the end of the quarter (actually, for the first day of the next quarter), as computed from U.S. Treasury bill prices obtained from the Center for Research in Security Prices (CRSP) at the University of Chicago. I thank Frederic Mishkin for providing the interest rate data and for useful advice. 


\section{REFERENCES}

Anderson, T. W.

(1958) Introduction to Multivariate Statistical Analysis. New York:

Bernanke, Ben

(1981) Bankruptcy, Liquidity, and Recession. American Economic

Review, 71: 155-159.

(1983a) On the Sources of Labor Productivity Variation in U.S.

Manufacturing, 1947-1980. Review of Economics and Statistics 65: 214-224.

(1983b) Non-Monetary Effects of the Financial Crisis in the Propagation of the Great Depression. American Economic Review, 73: 257-76.

(1984) Permanent Income, Liquidity, and Expenditure on Automobiles: Evidence from Panel Data. Quarterly Journal of Economics, 99: $\quad 587-614$.

and Mark Gertler

(1985) Banking in General Equilibrium. NBER Working Paper No. 1647.

Black, Fischer

(1982) General Equilibrium and Business Cycles. NBER Working Paper No. 950 .

(1972) Active and Passive Monetary Policy in a Neo-Classical Model. Journal of Finance, 27: 801-814.

Blanchard, Olivier and Mark Watson

(1984) Are Business Cycles All Alike? NBER Working Paper No. 1392.

Blinder, Alan

(1984a) Credit Rationing and Effective Supply Failures. Manuscript, Princeton University. 
(1984b) Notes on the Comparative Statics of a Stiglitz-Weiss Bank. Manuscript, Princeton University.

and Joseph Stiglitz

(1983) Money, Credit Constraints, and Economic Activity. American Economic Review, 73: 297-302.

Boyd, John and Edward Prescott

(1983) Financial Intermediaries. Manuscript, Minneapolis Federal

Reserve Bank and University of Minnesota.

Buiter, William H.

(1984) Granger - Causality and Policy Effectiveness. Economica 51: 151-62.

Cooley, Thomas F. and Stephen F. LeRoy

(1985) Atheoretical Macroeconomics: A Critique. Journal of Monetary Economics, 16: ??-??.

Fama, Eugene

(1985) What's Different About Banks? Journal of Monetary Economics, 15: $29-40$.

Fischer, Stanley

(1977) Long-term Contracts, Rational Expectations, and the Optima1

Money Supply Rule. Journal of Political Economy, 85:

191-205.

Fisher, Irving

(1933) The Debt-Deflation Theory of Great Depressions.

Econometrica, 1: 337-357.

Friedman, Benjamin

(1983) The Roles of Money and Credit in Macroeconomic Analysis. In

James Tobin, ed., Macroeconomics, Prices, and Quantities.

Washington, D.C.: Brookings Institution.

Friedman, Milton and Anna Schwartz

(1963) A Monetary History of the United States. Princeton:

Princeton University Press (for NBER). 
Gordon, Robert and Stephen King

(1982) The Output Cost of Disinflation in Traditional and Vector Autoregressive Models. Brookings Papers on Economic Activity, 1: 205-244.

Gray, Jo Anna

(1978) On Indexation and Contract Length. Journal of Political

Economy, 86:

Hall, Bronwyn

(1979)

Moments: The Moment Matrix Processor, User's Manual, Version

Hall, Robert

(1978)

Some Evidence on the Sources of Economic Fluctuations.

Manuscript, Stanford University.

and Frederic Mishkin

(1982) The Sensitivity of Consumption to Transitory Income:

Estimates from Panel Data on Households. Econometrica, 50:

461-481.

Hendershott, Patric

(1980) Rea1 User Costs and the Demand for Single-Family Housing. Brookings Papers on Economic Activity, 2: $401-452$.

Huizinga, John and Frederic Mishkin

(1984) Inflation and Real Interest Rates on Assets with Differing

Risk Characteristics. Journal of Finance, 39: 699-712.

Jaffee, Dwight and Kenneth Rosen

(1979) Mortgage Credit Availability and Residential Construction. Brookings Papers on Economic Activity, 2: 338-376.

Jaffee, Dwight and Thomas Russell

(1976) Imperfect Information, Uncertainty, and Credit Rationing. Quarterly Journal of Economics, 90: 651-666.

King, Robert and Charles Plosser

(1984) Money, Credit, and Prices in a Real Business Cycle. American Economic Review, 74: 363-380.

King, Stephen

(1982) Interest Rates and the Transmission of Monetary Fluctuations to Output and Prices. Manuscript, Northwestern University. 
Monetary Transmission: Through Bank Loans, or Bank Liabilities?

(1985) Manuscript, Stanford University.

Kydland, Finn and Edward Prescott

(1982) Time to Build and Aggregate Fluctuations. Econometrica, 50:

1345-1370.

Kydland, Finn E.

(1983) The Role of Money in a Competitive Theory of Business

Fluctuations. Working Paper E-83-10, Hoover Institution,

Stanford University.

Leamer, Edward

(1985) Vector Autoregressions for Causal Inference. In K. Brunner and A. Meltzer, eds., Understanding Monetary Regimes.

Amsterdam: North Holland.

Litterman, Robert and Laurence Weiss

(1985) Money, Real Interest Rates, and Output: A Reinterpretation of Postwar U.S. Data. Econometrica 53: 129-156.

Long, John and Charles Plosser

(1983) Real Business Cycles. Journal of Political Economy, 91:

39-69.

Lucas, Robert, Jr.

(1972) Expectations and the Neutrality of Money. Journal of

Economic Theory, 4: 103-124.

McCallum, Bennett T.

(1983) A Reconsideration of Sims' Evidence Concerning Monetarism. Economics Letters, 13: 167-71.

Mankiw, N. Gregory and Matthew Shapiro

(1985) Trends, Random Walks, and Tests of the Permanent Income Hypothesis. Journal of Monetary Economics, 16: 165-74.

Mehra, Yash P.

(1978) Is Money Exogenous in Money-Demand Equations? Journal of

Political Economy, 86, pt. 1: 211-28.

Porter, Richard D. and Edward K. Offenbacher

(1983) Empirical Comparisons of Credit and Monetary Aggregates with Vector Autoregressive Methods. Economic Review (Federa1

Reserve Bank of Richmond), 69: 16-29. 
Runkle, David

(1985) Vector Autoregression Reality. Brown University, Department of Economics working paper No. 85-86.

Sargent, Thomas and Christopher Sims

(1977) Business Cycle Modelling Without Pretending to Have Too Much A Priori Economic Theory. In Sims, ed., New Methods in Business Cycle Research. Minneapolis: Federa1 Reserve Bank.

Sims, Christopher

(1972) Money, Income, and Causality. American Economic Review 62: $\quad 540-552$.

(1980a) Macroeconomics and Reality. Econometrica, 48: 1-48.

(1980b) Comparison of Interwar and Postwar Business Cycles:

Monetarism Reconsidered. American Economic Review, 70: 250-257.

Stiglitz, Joseph and Andrew Weiss

(1981) Credit Rationing in Markets with Imperfect Information. American Economic Review, 71: 393-410.

Taylor, John

(1980) Aggregate Dynamics and Staggered Contracts. Journal of Political Economy, 88: 1-23.

Tobin, James

(1971)

Money and Income: Post Hoc Ergo Propter Hoc? in Essays in Economics, Vo1. 1: Macroeconomics, Amsterdam:

North-Holland.

Townsend, Robert

(1983) Financial Structure and Economic Activity. American Economic Review, 73: 895-911.

Zellner, Arnold

(1979) Causality and Econometrics. In K. Brunner and Meltzer, eds., Three Aspects of Policy and Policymaking: Knowledge, Data and Institutions. Amsterdam: North-Holland. 
1778 Zvi Griliches and Jacques Mairesse

1779 Behzad T. Diba and Herschel I. Grossman

1780 William H. Branson

1781 Martin Feldstein

1782 Tadashi Yamada

1783 Tadashi Yamada Tetsuji Yamada and Frank Chaloupka

1784 William $\mathrm{H}$. Branson Arminio Fraga and Robert A. Johnson

1785 Robert E. Hall

1786 N. Gregory Mankiw

1787 Joshua Aizenman

1788 N. Gregory Mankiw

1789 Charles R. Nelson and Andrew F. Siege 1

1790 Martin Feldstein

1791 Martin Feldstein and Gilbert Metcalf

1792 Martin Feldstein

1793 Robert J. Barro and Gary S. Becker

1794 Robert J. Barro
R\&D and Productivity Growth: Comparing

$12 / 85$ Japanese and U.S. Manufacturing Firms

Rational Bubbles in Stock Prices?

$12 / 85$

The Dynamic Interaction of Exchange

$12 / 85$

Rates and Trade Flows

$12 / 85$

The Second Best Theory of Differential

Capital Taxation

The Crime Rate and the Condition

$12 / 85$ of the Labor Market

A Vector Autoregressive Model

A Multinominal Logistic Approach to the

$12 / 85$ Labor Force Behavior of Japanese Married Women

Expected Fiscal Policy and the Recession of 1982

$12 / 85$

The Relation Between Price and Marginal

$1 / 86$ cost in U.S. Industry

The Allocation of Credit and Financial Collapse

Monopolistic Competition, Relative Prices and Output Adjustment in the Open Economy

The Equity Premium and the Concentration $1 \cdot 86$ of Aggregate Shocks

Long-Term Behavior of Yield Curves

U.S. Budget Deficits and the European

Economies: Resolving the Political Economy Puzzle

The Effect of Federal Tax Deductibility in State and Local Taxes and Spending

Supply Side Economics: 0ld Truths and $1 / 86$ New Claims

A Reformulation of the Economic Theory $1 / 86$ of Fertility

Reputation in a Model of Monetary Policy with Incomplete Information 